\title{
CARACTERIZAÇÃO DOS ÓLEOS DE ALGUMAS SEMENTES DE FRUTAS COMO APROVEITAMENTO DE RESÍDUOS INDUSTRIAIS
}

\author{
Characterization of some seed oils of fruits for utilization of industrial residues
}

\author{
Cíntia Nanci Kobori' ${ }^{1}$, Neuza Jorge ${ }^{2}$
}

\begin{abstract}
RESUMO
A finalidade deste estudo foi caracterizar os óleos extraídos das sementes de laranja, maracujá, tomate e goiaba, como aproveitamento de resíduos industriais. Os óleos foram extraídos das sementes em um extrator Soxhlet, utilizando como solvente o éter de petróleo e a caracterização dos mesmos foi realizada por meio de métodos analíticos padrões para óleos e gorduras (ácidos graxos livres, índices de peróxidos, refração, iodo, saponificação, matéria insaponificável e estabilidade oxidativa). As análises realizadas indicaram que esses óleos possuem características físico-químicas semelhantes a alguns óleos comestíveis, podendo ser uma nova fonte de óleos para o consumo humano.
\end{abstract}

Termos para indexação: Medidas físico-químicas, óleos extraídos, sementes, tomate, laranja, maracujá, goiaba.

\begin{abstract}
The purpose of this study was to characterize the extracted oils of the seeds of tomato, orange, passion fruit and guava with the objective of using industrial residues. The oils were extracted from the seeds with a Soxhlet extractor, using petroleum ether as solvent, and were characterized by standard methods for oil and fat analysis (free fatty acids, peroxide value, refractive index, iodine value, saponification value, unsaponifiable matter and oxidative stability). The analyses accomplished indicate that these oils possess similar physicochemical characteristics as some edible oils, them they can be a new source of oils for human consumption.
\end{abstract}

Index terms: physicochemical measures, oils, seeds, tomato, orange, passion fruit, guava.

(Recebido para publicação em 04 de junho de 2004 e aprovado em 27 de junho de 2005)

\section{INTRODUÇÃO}

As indústrias alimentícias brasileiras produzem resíduos que poderiam ter uma finalidade muito mais benéfica ao homem e ao meio ambiente. Muitos frutos comestíveis são processados para fabricação de sucos naturais, sucos concentrados, doces em conserva, polpas e extratos, os quais possuem sementes que são, muitas vezes, descartadas sendo que poderiam ser utilizadas para minimizar o desperdício de alimentos.

O descarte dos resíduos do processamento das frutas tropicais e subtropicais representa um crescente problema devido ao aumento da produção. Como este material é geralmente propenso a degradação microbiológica, isto limita uma exploração futura. Por outro lado, o custo da secagem, armazenagem e transporte de subprodutos são fatores economicamente limitantes. Por isso, os resíduos industriais são muitas vezes utilizados como ração animal ou na forma de fertilizantes. Porém, a demanda por ração pode variar e depender da produção agrícola, além do problema do descarte desses subprodutos ser agravado pelas restrições legais. Dessa maneira, uma utilização eficiente, econômica e segura para o meio ambiente, está se tornando mais importante especialmente devido à rentabilidade e aos possíveis empregos (SCHIEBER et al., 2001).

O tomate é cultivado mundialmente numa grande variedade de solos e condições climáticas. O processamento comercial de tomates em sucos, purês, polpas, catchup, sopas, etc, geram quantidades significantes de resíduos sólidos, compostos por peles, sementes e aparas. A principal parte do resíduo sólido da semente de tomate é uma inexplorada fonte de óleo não tradicional, contendo uma porcentagem de óleo acima de 38\% (SOGI et al., 1999).

O óleo dessa semente pode ser aproveitado para cosméticos e produtos farmacêuticos, como óleo comestível, em indústrias de verniz, etc. Daí, a importância de desenvolver uma extração tecnológica efetiva e uma caracterização de sua composição físico-química (ROY et al., 1996).

Já, a laranja é um dos frutos cítricos mais cultivados em algumas regiões do mundo. Geralmente, a fruta é consumida in natura ou processada para a obtenção de sucos de laranja, enquanto que as sementes são descartadas. Em estudos realizados com essas sementes,

${ }^{1}$ Aluna de Iniciação Científica - bolsista CNPq/PIBIC.

${ }^{2}$ Professora Doutora do Departamento de Engenharia e Tecnologia de Alimentos - Instituto de Biociências, Letras e Ciências Exatas/UNESP Campus de São José do Rio Preto - SP. 
Akpata \& Akubor (1999) observaram que o óleo continha alta quantidade de ácidos graxos insaturados e que quando refinado poderia ser utilizado na formulação de óleos comestíveis e de sopa industrializada.

As sementes de citros contêm 28 a 35\% de óleo, 40 a $49 \%$ de farinha e 23 a $25 \%$ de casca. O óleo é composto fundamentalmente por triacilgliceróis (> 95\%) e, em menores quantidades, por ácidos graxos livres, hidrocarbonetos, esteróis e matéria não-gordurosa, isto é, limonina e naringina. Uma importante característica química do óleo da semente, sobre o ponto de vista nutricional, é a distribuição dos ácidos graxos. Os seis principais ácidos graxos são: palmítico, palmitoléico, esteárico, oléico, linoléico e linolênico (NAGY et al., 1977).

Assim também, uma alternativa de aproveitamento dos subprodutos da industrialização do maracujá é a utilização na alimentação humana. As sementes são consideradas como boa fonte de óleo que pode ser utilizado nas indústrias alimentícias e, principalmente, nas de perfumes e aromas. De acordo com o Informe Agropecuário (2000), em estudos sobre a composição do óleo das sementes de maracujá (Passiflora edulis, Passiflora edulis f. flavicarpa e Passiflora foetida), observou-se a presença de 22 a $28 \%$ de óleo e que os ácidos graxos mais importantes foram o linoléico (55-66\%), o oléico (18-20\%) e o ácido palmítico (10-14\%). O conteúdo de ácido linolênico foi considerado baixo $(0,8-1,1 \%)$.

O óleo das sementes de maracujá possui coloração amarela, sabor agradável e odor suave, com as seguintes características físico-químicas: baixa secatividade, médio índice de saponificação e baixa estabilidade, sendo suscetível a rancidez oxidativa devido ao grande conteúdo de ácido linoléico. O óleo da semente de maracujá ainda pode ser utilizado para fabricação de sabonetes, tintas, vernizes e, após refinação ou hidrogenação, para fins comestíveis (MEDINA et al., 1980).

A goiaba, além de consumida crua ou natural, tem aplicações comerciais como a goiabada, geléia, pasta, fruta em calda, purê, alimentos para crianças, base para bebidas, refrescos, sucos, xaropes, vinhos e outros. A fruta é excepcionalmente rica em vitamina $\mathrm{C}$, superando o conteúdo nos sucos cítricos. Por isso, também são utilizadas como aditivos para outros sucos e purês, fortificando-os em vitamina C (MEDINA et al., 1978).

Prasad \& Azeemoddin (1994) constataram que o óleo de goiaba é uma boa fonte de ácido linoléico, como ácido graxo essencial, podendo ser utilizado com vantagens nutricionais, misturando-o com outros óleos comestíveis de alta saturação para resultar num novo óleo com valores nutricionais modificados.
Tais circunstâncias explicam a importância de conduzir estudos no Brasil sobre óleos extraídos das sementes de frutos que são geralmente descartadas, uma vez que não há renda para a venda de subprodutos e o depósito contínuo desse descarte poderia aumentar o custo do processamento. Ainda mais, se estes resíduos permanecerem inutilizados, não apenas aumentará o custo de venda do produto, mas também, irá agravar a poluição ambiental.

A finalidade deste estudo foi caracterizar físicoquimicamente, por meio de diversas metodologias, os óleos extraídos de sementes de tomate, laranja, maracujá e goiaba, utilizados na produção de extratos, polpas e sucos concentrados, como aproveitamento de resíduos industriais.

\section{MATERIAL E MÉTODOS}

\section{Amostras}

As amostras de sementes de frutos (tomate, laranja, maracujá e goiaba) foram provenientes das indústrias alimentícias Predilecta localizada em Matão-SP, Cutrale e Bios Industrial localizadas em Araraquara-SP. A indústria Predilecta forneceu os resíduos dos processamentos do tomate e da goiaba, constituídos de sementes, fibras, cascas e resquícios de polpa; a indústria Cutrale forneceu apenas as sementes que são descartadas para obtenção de suco concentrado de laranja; e a Bios Industrial forneceu o resíduo da concentração da polpa do maracujá compreendendo as sementes, resquícios de polpa e alguns pedaços de cascas. Essas amostras foram colocadas em sacos plásticos e armazenadas à temperatura próxima de $-20^{\circ} \mathrm{C}$.

Inicialmente, determinaram-se a porcentagem de umidade inicial e o teor lipídico das amostras. Em seguida, estas foram secas em estufa de circulação forçada de ar, utilizando temperatura em torno de $45^{\circ} \mathrm{C}$ até que atingissem aproximadamente $10 \%$ de umidade. O óleo foi extraído das sementes, previamente trituradas, em um extrator Soxhlet utilizando como solvente o éter de petróleo $\left(40-60^{\circ} \mathrm{C}\right)$. Esses óleos foram coletados em recipientes de vidro âmbar e armazenados à temperatura de aproximadamente $-20^{\circ} \mathrm{C}$ para evitar posteriores alterações oxidativas incontroláveis. Foram descongelados apenas no momento das análises. Os óleos foram caracterizados de acordo com métodos padrões de análises de óleos e gorduras (AOCS, 1990, 1993; HARTMAN \& ESTEVES, 1982). As análises foram realizadas em duplicatas. 


\section{Determinações analíticas}

Determinação da umidade - o método determina umidade e materiais (substâncias) voláteis, expressos em porcentagem a partir da perda de peso sobre o peso da amostra. Foi utilizado o método AOCS Bc 2-49 (AOCS, 1990).

Determinação do teor lipídico - foi utilizado o método Soxhlet descrito pela AOCS Bc 3-49 (AOCS, 1993), expresso em porcentagem, determinado de acordo com o equipamento de extração de gordura, modelo MA 490 da marca Marconi. Esse método determina as substâncias extraídas com éter de petróleo, sob as condições do teste.

Ácidos graxos livres - denomina-se "grau de acidez" à porcentagem de ácidos graxos livres que contém um óleo, expressos como ácido oléico. Foi utilizado o método AOCS Cd 3d-63 (AOCS, 1993).

Índice de peróxidos - expressos em milequivalentes de oxigênio ativo contidos em um quilograma de óleo, calculado a partir do iodo liberado do iodeto de potássio, operando nas condições indicadas no método proposto pela AOCS Cd 8-53 (AOCS, 1993).

Índice de refração - foram utilizados o método AOCS Cc 7-25 (AOCS, 1993) e um refratômetro de Abbé. Fez-se a leitura na escala que resulta diretamente o índice de refração absoluto a $40^{\circ} \mathrm{C}$.

Índice de iodo - é a medida da insaturação de óleos e gorduras e é definido como a quantidade de halogênio em gramas, calculado como iodo absorvido por 100 gramas de amostra. Para esta determinação foi utilizado o método AOCS Cd 1 - 25 (AOCS, 1993).

Índice de saponificação - é definido pela quantidade em miligramas de hidróxido de potássio necessária para saponificar 1 grama de óleo ou gordura. Foi utilizado o método recomendado pela AOCS Cd 3c - 91 (AOCS, 1993).

Matéria insaponificável - corresponde à quantidade total de substâncias dissolvidas nos óleos e gorduras que após saponificação com álcalis são insolúveis em solução aquosa, mas solúveis em solventes comuns de gorduras. Foi empregado o método proposto por Hartman \& Esteves (1982).

Medida da estabilidade oxidativa(método Rancimat) - obtida pelo método AOCS Cd 12b-92 (AOCS, 1993), empregando 3 gramas de óleo, temperatura de $100^{\circ} \mathrm{C}$ e fluxo de ar de $20 \mathrm{~L} / \mathrm{h}$. A curva de condutividade elétrica $\mathrm{x}$ tempo foi automaticamente registrada com o decorrer da reação e do teste, em que o período de indução foi determinado em horas. Foi utilizado o Rancimat, marca METROHM, modelo 743.

\section{RESULTADOS E DISCUSSÃO}

As sementes e as cascas são os principais resíduos do processamento de frutos, podendo ser utilizadas principalmente como ração animal. Há vários estudos que reportam o seu potencial nutricional. Neste trabalho foram realizadas apenas as análises de umidade e teor lipídico para as sementes, enquanto que para os óleos extraídos foram empregadas as determinações físico-químicas: ácidos graxos livres, índice de peróxidos, índice de refração, índice de iodo, índice de saponificação, matéria insaponificável e estabilidade oxidativa.

\section{Análises nas amostras}

$\mathrm{Na}$ Figura 1 apresentam-se os resultados em porcentagem obtidos das determinações de umidade, teor lipídico e matéria seca dos resíduos úmidos dos processamentos do tomate, da laranja, do maracujá e da goiaba.

\section{Umidade}

Em relação à umidade inicial dos resíduos, verificaram-se 80,9, 55,4, 38,2 e 43,3\% de umidade para o resíduo de tomate, laranja, maracujá e goiaba, respectivamente.

O resíduo do tomate possui esta elevada umidade, pois de acordo com Minani \& Fonseca (1985), durante o processamento do tomate, o resíduo é separado da polpa através das extratoras e refinadoras. Como estas não exercem uma elevada pressão na separação do resíduo, este contém ainda um elevado teor de umidade (suco) que geralmente está ligada às substâncias pécticas aderidas às sementes e de difícil remoção.

$\mathrm{O}$ valor determinado para a umidade das sementes de laranja foi próximo ao encontrado por Souza Júnior (1974) para os cultivares Hamlin, Pineapple e March, cujos valores encontrados foram de 56,50 e $56 \%$, respectivamente.

Já, a umidade encontrada para o resíduo do maracujá foi superior a umidade determinada por Medina et al. (1980) para as sementes de maracujá $(4,39 \%)$, visto que o resíduo obtido da indústria Bios Industrial continha além das sementes, parte do suco e da polpa.

Da mesma forma, o valor obtido na análise de umidade do resíduo do processamento da goiaba foi bem maior que o encontrado por Prasad \& Azeemoddin (1994), já que estes estudaram apenas as sementes $(4,1 \%)$. O resíduo de goiaba coletado neste trabalho continha em maior parte sementes, porém, estas estavam envoltas por uma parte de polpa deixando-a úmida. 


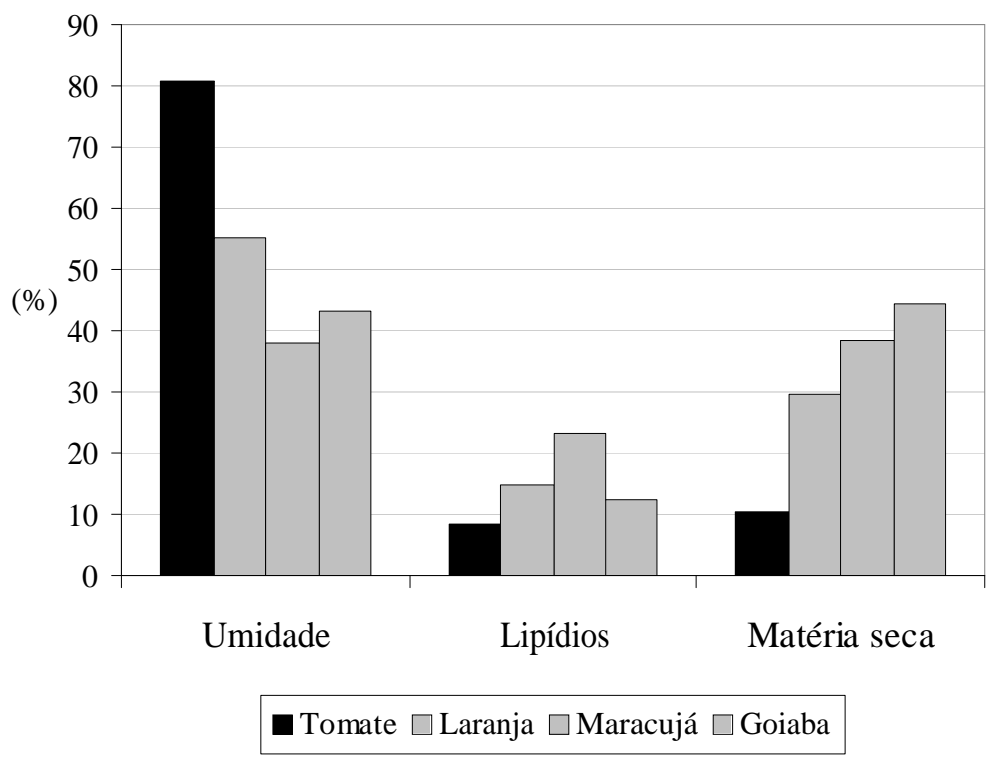

FIGURA 1 - Umidade, teor lipídico e matéria seca dos resíduos obtidos das indústrias alimentícias Predilecta, Cutrale e Bios Industrial.

A umidade da semente é importante para o rendimento do óleo obtido. A umidade mais indicada para as sementes de citros ainda não é conhecida, mas na prática são secas para obterem umidade em torno de 6 a $10 \%$ (SOUZA JÚNIOR, 1974).

Neste trabalho, os resíduos do processamento de tomate, laranja, maracujá e goiaba, foram secos durante aproximadamente 10 horas, em estufa de circulação forçada de ar, à temperatura de $45^{\circ} \mathrm{C}$, atingindo assim, umidades de $8,5 \%, 8,5 \%, 9,0 \%$ e $11,2 \%$, respectivamente.

\section{Teor lipídico}

No resíduo compreendendo sementes, fibras, cascas e polpa de tomate, verificou-se um conteúdo de lipídios superior ao reportado por Minani \& Fonseca (1985) que encontraram 5,43\% e inferior ao valor de 19,22\% verificado por Barcelos et al. (1992). Analisando somente as sementes de tomate, Al-Wandawi et al. (1985), Barcelos et al. (1992), Minani \& Fonseca (1985), Roy et al. (1996), Rymal \& Nakayama (1974) e Sogi et al. (1999) encontraram teores de lipídios de 19,33, 14,5, 27,1, 19,22, 29 e 38\%, respectivamente. Provavelmente, essas diferenças sejam provenientes de variações de métodos empregados na extração do resíduo industrial e ainda nos cultivares de tomates utilizados.

Em estudos realizados por Nagy et al. (1977), Romero et al. (1988) e Souza Júnior (1974), encontraram 24, 28-35 e
$32,25 \%$ de teor lipídico para a semente de laranja, respectivamente. Estes valores são superiores ao obtido neste estudo (15\%). Esta diferença pode ser explicada devido às variações do processamento utilizado nas indústrias, nos diferentes métodos empregados para a extração de óleos e nos cultivares de laranja.

O resíduo de maracujá apresentou porcentagem de lipídios próxima às verificadas por alguns autores (CORREA et al., 1994; HENDERSON et al., 1978; MEDINA et al., 1980), que encontraram $25,24,5$ e $27 \%$, respectivamente, significando que estas possuem um alto rendimento em óleo.

Schieber et al. (2001) relataram em seus estudos uma porcentagem de lipídios de aproximadamente 5-13\% nas sementes de goiaba, valor inferior ao obtido neste trabalho (12,3\%). Porém, Prasad \& Azeemoddin (1994) encontraram um teor lipídico para as sementes de goiaba em torno de $16 \%$. Segundo estes mesmos autores, essas diferenças nos valores de teor de lipídios podem estar relacionadas às tecnologias mais modernas, aos novos cultivares altamente produtivos após o enxerto e aos fatores ambientais.

Outro fator que pode ter ocasionado essas diferenças nos teores lipídicos é o período de armazenagem das sementes antes da extração do óleo, pois, segundo Romero et al. (1988), quando as sementes são armazenadas em freezer a quantidade de óleo que é extraída decresce. Porém, as características e a composição não são significantemente alteradas. 


\section{Análises nos óleos extraídos}

$\mathrm{Na}$ Tabela 1 apresentam-se as características físicoquímicas dos óleos extraídos das sementes de tomate, laranja, maracujá e goiaba.

\section{Ácidos graxos livres}

As porcentagens de ácidos graxos livres determinadas para os óleos de tomate e goiaba foram baixas podendo-se constatar que as matérias-primas eram de boa qualidade, pois os valores obtidos foram inferiores a $2 \%$, valor este considerado limite para a maioria dos óleos vegetais brutos no Brasil, conforme a portaria 482/99 ANVISA (BRASIL, 1999). Já, o valor de ácidos graxos livres encontrado para o óleo extraído da semente de laranja foi de 3,95\%, valor superior ao obtido por Nagy et al. (1977), que encontraram de 1,35 a 2,18\% para diversos cultivares de laranja. O óleo de maracujá também apresentou elevada porcentagem de ácidos graxos livres (7,35\%).

\section{Índice de peróxidos}

A presença de peróxidos indica que, de alguma forma, o óleo recebeu um tratamento inadequado. Como os valores obtidos para o tomate $\left(10,29\right.$ meq $\left.\mathrm{kg}^{-1}\right)$ e para a laranja $(29,4$ meq $\mathrm{kg}^{-1}$ ) foram elevados, o processo de extração por solvente, a partir do resíduo seco em estufa pode ter provocado uma oxidação durante a secagem, já que foi utilizada ventilação forçada por um período médio de 8 horas. Os baixos índices de peróxidos para os óleos de maracujá $\left(0,59 \mathrm{meq} \mathrm{kg}^{-1}\right)$ e goiaba $\left(0,2\right.$ meq $\left.\mathrm{kg}^{-1}\right)$, devem-se à baixa umidade inicial das sementes, necessitando um período bem menor (aproximadamente 5 e 3 horas, respectivamente) na estufa de circulação forçada de ar para atingir a umidade final desejada.

\section{Índice de refração}

Com respeito aos resultados encontrados neste trabalho, observa-se que os índices de refração à temperatura de $40^{\circ} \mathrm{C}$ para os óleos brutos extraídos das sementes foram 1,4708 para o óleo de tomate; 1,4651 para o óleo de laranja; 1,4691 para o óleo de maracujá e 1,4605 para o óleo de goiaba. O valor para o óleo de laranja está de acordo com o encontrado por Nagy et al. (1977), em estudos com diversos cultivares de laranja (1,4608 - 1,4714), e coerente com o valor obtido por Romero et al. (1988), que encontraram 1,4710 à temperatura de $20^{\circ} \mathrm{C}$. O valor encontrado por Medina et al. (1980) para o óleo de maracujá foi 1,5729 à temperatura de $25^{\circ} \mathrm{C}$, como este índice varia na razão inversa da temperatura, pode-se considerar estes resultados satisfatórios. Já, para o óleo de semente de goiaba, o valor obtido foi inferior ao reportado por Prasad \& Azeemoddin (1994) que encontraram 1,4772 à temperatura de $40^{\circ} \mathrm{C}$.

\section{Índice de iodo}

Os óleos extraídos neste estudo apresentaram índices de iodo $\left(128,59,97,99,124,36\right.$ e $\left.134,3 \mathrm{gI}_{2} 100 \mathrm{~g}^{-1}\right)$ semelhantes aos valores reportados pelos autores Medina et al. (1980), Nagy et al. (1977), Prasad \& Azeemoddin (1994) e Sogi et al. (1999) que encontraram para os óleos de tomate, laranja, maracujá e goiaba os valores 118, 86,1 - 101,7, 137,5 e $134 \mathrm{gI}_{2} 100 \mathrm{~g}^{-1}$, respectivamente, indicando que os óleos continham um alto grau de insaturação. Esses valores também são semelhantes ao do óleo de soja (120-143 gI $100 \mathrm{~g}^{-1}$ ) e de algodão (99-119 $\mathrm{gI}_{2} 100 \mathrm{~g}^{-1}$ ), conforme Brasil (1999). Além disso, os óleos de tomate, maracujá e goiaba podem ser classificados como óleos semi-secos e o de laranja como não-seco.

TABELA 1 - Características físico-químicas dos óleos extraídos das sementes de tomate, laranja, maracujá e goiaba.

\begin{tabular}{|c|c|c|c|c|}
\hline \multirow[t]{2}{*}{ Determinações físico-químicas } & \multicolumn{4}{|c|}{ Óleos } \\
\hline & Tomate & Laranja & Maracujá & Goiaba \\
\hline Ácidos graxos livres $(\%)^{\mathrm{a}}$ & 0,5 & 3,95 & 7,35 & 0,23 \\
\hline Índice de peróxidos $\left(m e q \mathrm{~kg}^{-1}\right)^{\mathrm{a}}$ & 10,29 & 29,4 & 0,59 & 0,2 \\
\hline Índice de refração $\left(40^{\circ} \mathrm{C}\right)^{\mathrm{b}}$ & 1,4708 & 1,4651 & 1,4691 & 1,4605 \\
\hline Índice de iodo $\left(\mathrm{gI}_{2} 100 \mathrm{~g}^{-1}\right)^{\mathrm{a}}$ & 128,59 & 97,99 & 124,36 & 134,3 \\
\hline Índice de saponificação $\left(\mathrm{mg} \mathrm{KOH} \mathrm{g}^{-1}\right)^{\mathrm{a}}$ & 172,86 & 181,05 & 174,97 & 189,91 \\
\hline Matéria insaponificável $(\%)^{\mathrm{a}}$ & 2,1 & 0,67 & 0,91 & 0,71 \\
\hline Medida da estabilidade oxidativa $(\mathrm{h})^{\mathrm{c}}$ & 14,41 & 3,25 & 16,50 & 20,33 \\
\hline
\end{tabular}

a Valores obtidos da média dos resultados das análises feitas em duplicatas.

${ }^{\text {b }}$ Valor obtido da média dos resultados das análises feitas em triplicatas.

c $3 \mathrm{~g}$ de óleo, temperatura de $100^{\circ} \mathrm{C}$, fluxo de ar: $20 \mathrm{~L} \mathrm{~h}^{-1}$.

Ciênc. agrotec., Lavras, v. 29, n. 5, p. 1008-1014, set./out., 2005 


\section{Índice de saponificação}

Os valores encontrados para o índice de saponificação das amostras de óleo de tomate, laranja, maracujá e goiaba foram 172,86, 181,05, 174,97 e 189,91 mg $\mathrm{KOH} \mathrm{g}{ }^{-1}$ de óleo, respectivamente. Todos os valores obtidos neste estudo foram inferiores aos encontrados por Medina et al. (1980), Nagy et al. (1977), Prasad \& Azeemoddin (1997) e Sogi et al. (1999) cujos valores foram 190, 192,0-197,5, 191,3 e 196,0 mg KOH g ${ }^{-1}$ para os óleos de tomate, laranja, maracujá e goiaba, respectivamente. Entretanto, esses valores são semelhantes a alguns óleos comestíveis, como os óleos de palma (196-205 mg KOH g${ }^{-1}$ ) e de milho (187-196 mg KOH g ${ }^{-1}$ ).

\section{Matéria insaponificável}

Os valores de matéria insaponificável foram 2,1, 0,67, 0,91 e $0,72 \%$ para os óleos brutos obtidos das sementes de tomate, laranja, maracujá e goiaba, respectivamente. Os valores encontrados para os óleos de tomate, maracujá e goiaba foram superiores aos reportados por Sogi et al. (1999) que verificaram apenas $1,4 \%$ para o tomate, por Medina et al. (1980) que obtiveram 0,77\% para o maracujá e por Prasad \& Azeemoddin (1997) que encontraram 0,49\% para a goiaba. Já, a porcentagem obtida para o óleo de laranja foi próximo ao reportado por Romero et al. (1988), que encontraram $0,65 \%$. Porém, segundo Mehlenbacher (1977), das análises de óleos e gorduras, a determinação da matéria insaponificável é um dos métodos que menos satisfaz. Isto ocorre pela falta de segurança e precisão nos resultados obtidos, principalmente por causa de pesquisadores distintos.

\section{Medida da estabilidade oxidativa}

Com respeito aos resultados encontrados neste trabalho, observa-se que os índices de estabilidade oxidativa obtidos através do método Rancimat à temperatura de $100^{\circ} \mathrm{C}$ e fluxo de ar em $20 \mathrm{~L} / \mathrm{h}$, foram 14,41 , 3,25, 16,5 e 20,33 horas, para os óleos de tomate, laranja, maracujá e goiaba, respectivamente. Esses índices foram semelhantes aos valores obtidos para os óleos de milho (19,07 horas), soja (12,47 horas) e girassol (10,01 horas) determinados por Del Ré (2003). Porém, o óleo de laranja obteve um valor muito inferior aos outros óleos, possivelmente devido ao alto índice de peróxidos e ao grau de insaturação do óleo.

\section{CONCLUSÕES}

As análises realizadas nos óleos brutos de tomate, laranja, maracujá e goiaba indicam que estes possuem características físico-químicas semelhantes a alguns óleos comestíveis, podendo ser uma nova fonte de óleos para o consumo humano conforme relata a literatura.

A utilização dos resíduos do processamento de tomate, laranja, maracujá e goiaba para a extração de óleo poderia aumentar a renda sobre a matéria-prima e, ao mesmo tempo, ajudar a minimizar o problema que a deposição desses resíduos pode causar, tendo em vista os elevados volumes gerados de resíduos nas indústrias dos processamentos do tomate, laranja, maracujá e goiaba, acrescido à necessidade de se expandir a produção de alimentos para a população, e ainda, considerando a escassez de dados sobre o valor nutritivo dos referidos subprodutos, são necessárias mais pesquisas para avaliar as propriedades nutricionais dos resíduos totais e das sementes.

\section{AGRADECIMENTOS}

Ao PIBIC/CNPq pela concessão de bolsa de Iniciação Científica e às empresas Sucocítrico Cutrale Ltda. e Bios Industrial Ltda., de Araraquara-SP e I.C.C.A. Predilecta Ltda., de Matão-SP, pela concessão dos resíduos de laranja, maracujá, tomate e goiaba, respectivamente.

\section{REFERÊNCIAS BIBLIOGRÁFICAS}

AKPATA, M. I.;AKUBOR, P. I. Chemical composition and selected functional properties of sweet orange (Citrus sinensis) seed flour. Plant Foods Human Nutrition, The Hague, v. 54, p. 353-362, 1999.

AL-WANDAWI, H.; ABDUL-RAHMAN, M.; ALSHAIKHLY, K. Tomato processing waste as essential raw materials source. Journal Agricultural Food Chemistry, Easton, v. 33, p. 804-807, 1985.

AMERICAN OIL CHEMISTS' SOCIETY. Official methods and recommended practices. 4 . ed. Champaign, 1990. v. 2.

AMERICAN OIL CHEMISTS' SOCIETY. Official methods and recommended practices. 4 . ed. Champaign, 1993. v. 3.

BARCELOS, M. F. P.; MELLO, L. C. P.; CORREA, M. A.; VILELA, M. J. C. Subprodutos do processamento de tomate: avaliação química e biológica. Boletim da Sociedade Brasileira de Ciência e Tecnologia de Alimentos, Campinas, v. 26, p. 108-117, 1992. 
BRASIL. Resolução nº 482, de 23 de setembro de 1999. Regulamento técnico para fixação de identidade e qualidade de óleos e gorduras vegetais. Diário Oficial da União, Brasília-DF, v. 196, 13 out. 1999. Seção I, p. 82-87.

CORREA, N. C. F.; MEIRELES, M. A. A.; FRANCA, L. F.; ARAUJO, M. E. Extraction of passion fruit (Passiflora edulis) seed oil with supercritical CO2. Ciência e Tecnologia de Alimentos, Campinas, v. 14, p. 29-37, 1994.

DEL RÉ, P. V. Comportamento de óleos vegetais em frituras descontínuas de produtos pré-fritos congelados. [S.1.: s.n.], 2003.

HARTMAN, L.; ESTEVES, W. Tecnologia de óleos e gorduras vegetais. São Paulo: Comércio, Ciência e Tecnologia, 1982. (Secretaria de Estado da Indústria, 13).

HENDERSON, H. M.; SAINT-HILAIRE, P.; SCHULTHESS, W. Some impressions of food science and technology in East Africa. In: INTERNATIONAL CONGRESS FOOD SCIENCE TECHNOLOGY ABSTRACTS, 1978, Oxford. Resumes... Oxford: [s.n.], 1978.

INFORME AGROPECUÁRIO. Belo Horizonte, v. 21, n. 206, p. $84-85$, set./out. 2000.

MEDINA, J. C.; GARCIA, J. L. M.; KATO, K.; MARTÍN, Z. J. de; VIEIRA, L. F.; ERNESTO, O. V. Goiaba: da cultura ao processamento e comercialização. São Paulo: Instituto de Tecnologia de Alimentos, 1978. cap. 3. (Série Frutas Tropicais, 6).

MEDINA, J. C.; GARCIA, J. L. M.; LARA, J. C. C.; TOCCHINI, R. P.; HASHIZUMI, T.; MORETTI, V. A.; CANTO, W. L. Maracujá: da cultura ao processamento e comercialização. São Paulo: Instituto de Tecnologia de Alimentos, 1980. cap. 3. (Série Frutas Tropicais, 9).

MEHLENBACHER, V. C. Análisis de grasas y aceites. Bilbao: Urmo, 1977. (Enciclopedia de la química industrial, 6).
MINANI, K.; FONSECA, H. Tomate: produção, préprocessamento e transformação agroindustrial. Campinas: FEALQ, 1985. (Série extensão agroindustrial, 8).

NAGY, S.; SHAW, P. E.; VELDHUS, M. K. Citrus science and technology. Westport: Avi, 1977. v. 1.

PRASAD, N. B. L.; AZEEMODDIN, G. Characteristics and composition of guava (Psidium guajava L.) seed and oil. Journal of the American Oil Chemistry Society, Chicago, v. 71, n. 4, 1994.

ROMERO, F.; DOBLADO, J.; COTA, J. Characterization of bitter orange (Citrus aurantium L.) seed oil. Grasas y Aceites, Sevilla, v. 39, n. 6, p. 353-358, 1988.

ROY, B. C.; GOTO, M.; HIROSE, T. Temperature and pressure effects on supercritical $\mathrm{CO}_{2}$ extraction of tomato seed oil. Journal of Food Science and Technology, Trivandrum, v. 31, p. 137-141, 1996.

RYMAL, K. S.; NAKAYAMA, T. O. M. Major carotenoids of seeds of three cultivars of the tomato, Lycopersicon esculentum L. Journal Agricultural Food Chemistry, Easton, v. 22, n. 4, p. 715-717, Mar. 1974.

SCHIEBER, A.; STINTZING, F. C.; CARLE, R. Byproducts of plant food processing as a source of functional compounds: recent developments. Trends Food Science Technology, Cambridge, v. 12, p. 401-413, 2001 .

SOGI, D. S.; KIRAN, J.; BAWA, A. S. Characterization and utilization of tomato seed oil from tomato processing waste. Journal of Food Science and Technology, Trivandrum, v. 36, n. 3, p. 248-249, 1999.

SOUZA JÚNIOR, A. J. Considerações sobre o aproveitamento das sementes de citros. Boletim do Instituto de Tecnologia de Alimentos, Campinas, n. 39, p. 3-24, set. 1974. 